\title{
Hispanismo y patrimonio arqueológico ibérico
}

\section{Hispanism and Iberian Archaeological Heritage}

\author{
Carmen Aranegui Gascó \\ Universitat de València \\ Carmen.Aranegui@uv.es
}

Fecha de recepción: 03-11-2019

Fecha de aceptación: 28-01-2020

\section{RESUMEN}

Este artículo apoya la existencia de arqueólogos hispanistas entre el siglo XIX y la primera mitad del XX. Destacan los profesionales franceses que reconocieron y divulgaron la singularidad de España desde sus orígenes, alentados por la sensibilidad romántica de la época. El itinerario de la Dama de Elche hasta su exposición en el Museo del Louvre es el mejor testimonio de este fenómeno.

Palabras clave: Historiografía española, Hispanistas, Arqueología ibérica, Dama de Elche Período: Prehistoria

\section{ABSTRACT}

This paper defends the existence of Hispanist archaeologists between the 19th and the first half of the 20th century. French researchers in particular, who recognised and disseminated Spanish singularity since its origins, encouraged by the Romantic sensibility of the era. The odyssey of the Lady of Elche en route to the Louvre Museum is the best testimony of this phenomenon.

Key words: Spanish Historiography, Hispanists, Iberian Archaeology, Lady of Elche.

Period: Prehistory

\section{INTRODUCCIÓN}

Inicio esta contribución al dosier El hispanismo en la historiografía con un breve apunte acerca de por qué determinados arqueólogos extranjeros merecen la consideración de hispanistas. Se trata de reconocer a aquellos que se dedicaron a descubrir y divulgar, entre el siglo XIX y comienzos del XX, durante un periodo limitado, la singularidad española a partir de obras figurativas arqueológicas anteriores a la conquista romana, destacadas por no ser un simple trasunto de las grandes civilizaciones. Cuando se creó la Asociación 
Internacional de Hispanistas (Oxford, 1962), ya solo figuraron como tales los expertos en espacios lingüísticos relacionados con España y América Latina (Pierce y Jones, 1964), algunos de los cuales han propuesto un uso restrictivo del término para el Siglo de Oro, centrándolo en el cervantismo (Canavaggio, 1987). También hay quienes objetan que llevar la hispanística a etapas previas a lo que entienden como nación española es, cuanto menos, paradójico (Pellistrandi, 2013). Por todo ello me limitaré a la cronología indicada, en la que hubo publicaciones e instituciones que dieron soporte a arqueólogos cuya razón de ser fue revelar los orígenes de la genialidad hispana, asociándola al arte primitivo que pronto se llamó ibérico (Paris, 1897: 137-168) y al arte rupestre de la cornisa cantábrica (Cartailhac, 1902: 348-354), contemplados en distintos capítulos de este volumen.

Fue un hecho que sobrevino pasada una generación o más del final de la guerra del Francés, después llamada de la Independencia (1808-1814), contexto que merece la toma en consideración de enfoques alternativos o complementarios (Niño, 1988; Ayarzagüena, Mora y Salas, 2017) a los más atendidos por una historiografía convencional que reitera las desavenencias franco-españolas. El botín artístico y archivístico español, patrullado por los ejércitos napoleónicos y sus mariscales, no fue lo que desencadenó en Francia el movimiento hispanista. Este surgió más tarde, cuando una elite intelectual se rindió ante el potencial creativo español, que algunos arqueólogos remontaron a culturas pretéritas. Por otra parte, aunque prevalece la opinión de que tal movimiento irrumpió sobre un país económicamente decrépito, virgen para quienes se consagraron a su estudio con el entusiasmo del converso, también esta afirmación puede matizarse (Papí, Mora y Ayarzagüena, 2012), sin negar que la decadencia encontró eco, si acaso veladamente, en las mentalidades reticentes al españolismo, proclives a minorizarse en previsión de la descalificación (Ladero, 1996: 5-50). Quizá por ello no se ha resaltado suficientemente que el caso de estos primeros arqueólogos tiene sus particularidades. Mostraban una actitud respaldada por una preparación superior a la de los arqueólogos españoles, pero no se comportaron como si estuvieran en una tierra de nadie, ni fueron unos exaltados, ni colonizadores, ni prepotentes, sino que aumentaron el sector de quienes admiraban la esporádica genialidad de una España que, ciertamente, estaba en trance de liquidar su imperio colonial, en otros tiempos universal, pero con la que se podía dialogar porque había contribuido al descubrimiento de Pompeya y Herculano, contaba con instituciones académicas solventes desde, al menos, el reinado de Felipe V (1700-1743) (Díaz-Andreu, Mora y Cortadella, 2009), con el Boletín de la Real Academia de la Historia (1877), además de tener museos como el del Prado desde 1819 y el Arqueológico Nacional desde 1867. En el tránsito al siglo XX, Europa volvía a admirar a una España que tenía limitaciones, en buena medida atribuidas a la falta de proyección internacional de sus eruditos. La Junta de Ampliación de Estudios (1907) trató de abrir horizontes a la investigación española y obtuvo buenos resultados, admitiendo que un cierto cosmopolitismo era indispensable para tener voz autorizada en todo tipo de saberes, criterio que duró hasta que el primer franquismo rompió su línea de acción (Duplá, dell’Elicine y Pérez Mostazo, 2018).

Ejemplo ambiguo del rango en que se auto-contemplaba España a finales del XIX se deduce de su participación en las exposiciones universales de Viena (1873), Filadelfia (1876), París (1878) (Lasheras, 2009) y, algo después, de Roma (1911) (Tortosa, 2017: 11331147), en las que se privilegió una visión autóctona y populista del país. Tanto progresistas (Fernández de los Ríos, 1878) como regionalistas (Llorente, 1879) criticaron severamente que en algunas de estas muestras se hiciera gala de un pueblo ignorante y de una sociedad reticente a la modernidad, aunque esta había sido más o menos la tónica desde la Exposición Mundial de Londres en el Crystal Palace (1851) (Méndez, 2006: 23-42). Pero en aquellas fue donde se expusieron por primera y única vez, sin embargo, reproducciones de esculturas 
del Cerro de los Santos (Montealegre del Castillo) (fig. 1), clasificadas oficialmente como visigodas, con alguna falsificación incluida (Chapa y González Alcalde, 2013: 115-130) que suscitaron en París, por una parte, el rechazo, hasta el punto de ser retiradas en su totalidad del pabellón de estilo neo-árabe con que España había concurrido y, por otra, para algún entendido capaz de distinguir lo auténtico de lo falso, como fue el caso Heuzey (1831-1922) y principalmente de Mélida (1856-1933) (1903 a 1905), el presentimiento de un arte inédito, digno de interlocutores más instruidos que los que había tenido (Aranegui, 2018: 28-37).

Figura 1. Oferente del Cerro de los Santos descubierta antes de 1870, siglos III-II a. C.

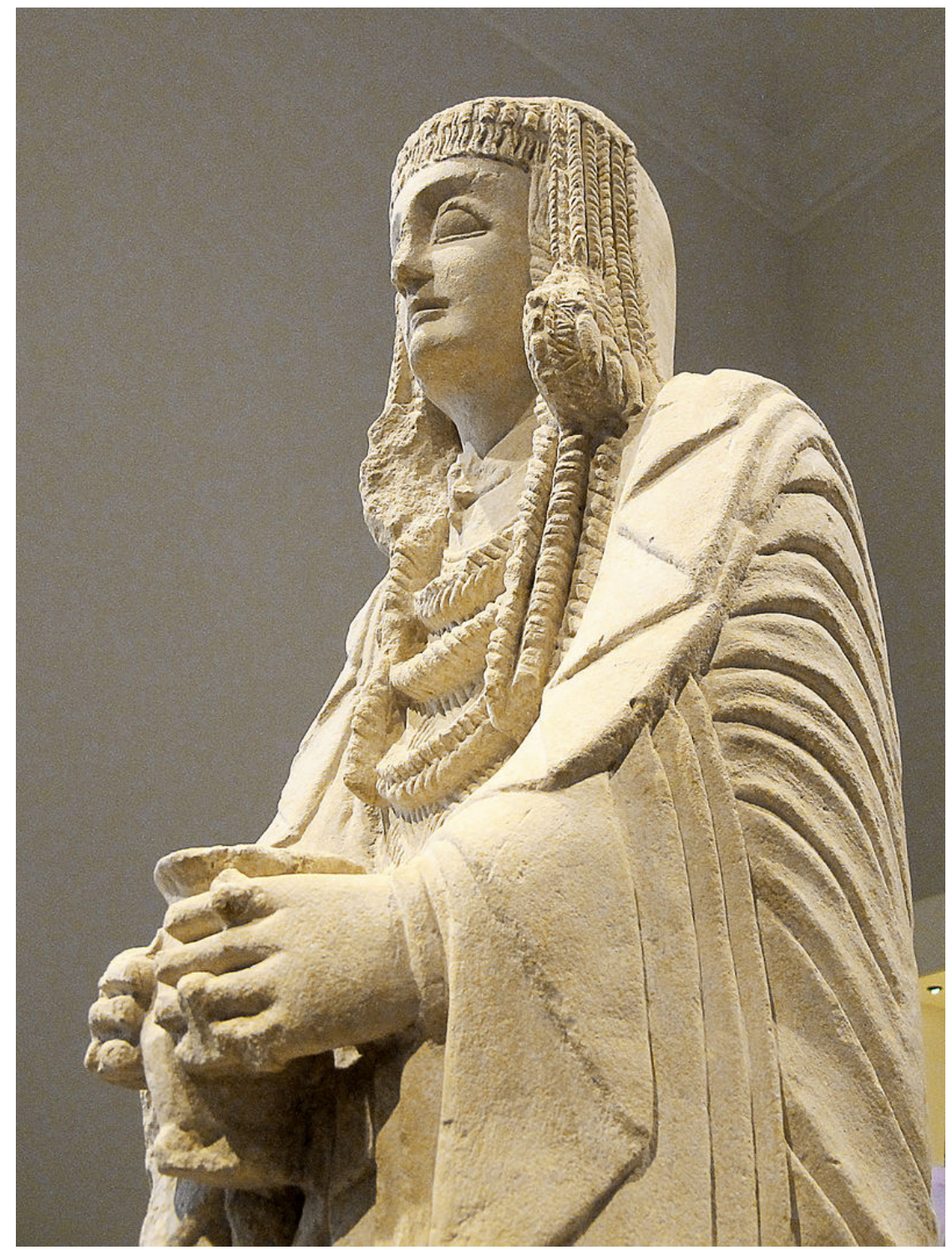

Fuente: Museo Arqueológico Nacional

En buena medida, España era vista en el siglo XIX deficitaria en cuanto a arqueólogos solventes porque, incluso antes de la unificación de Italia (1860), se había desentendido de las ciudades del Vesubio, que no fueron reemplazadas por la exploración arqueológica de Grecia, del Próximo Oriente o de Egipto, a diferencia de lo que hacía la Europa ilustrada. Las Bellas Artes de la Antigüedad tenían para los españoles un soporte que no iba más allá del saber de algunos eclesiásticos, como Ortiz (1739-1822), que tradujo el Tratado de Vitruvio, hasta que la creación de la Academia Española en Roma (1873) y, mucho después, 
de la Escuela Española de Historia y Arqueología en Roma (1910), del Institut d'Études hispaniques de la Sorbona (1919) y del Colegio de España en París (1935) dieran acceso a ambientes internacionales, sin llegar a constituir una red comparable a la que existía para franceses, ingleses, italianos o alemanes. Solo la Junta de Ampliación de Estudios posibilitó que se cursaran estudios fuera del país, como fue el caso de Bosch Gimpera (1891-1974), alumno de la Universidad de Berlín entre 1911 y 1914 (Gracia Alonso, 2011) .

De todos modos conviene tener en cuenta la inestabilidad política de aquellos tiempos porque el fracaso de la expedición francesa a Egipto, Turquía y Siria (1798-1801) desencadenó el declive de su arqueología en Oriente Próximo, a la vez que la independencia norteamericana, la caída de Maximiliano I en Méjico y las disputas sobre África menguaron los campos de acción de otros países con iniciativas fuera de sus fronteras, panorama que se agravaría durante la Gran Guerra (1914-1918). Ante tales limitaciones, la Europa que respiraba aires románticos, con la actitud vital de los implicados, dirigió su mirada hacia un país reputado por haber alumbrado no solo a los creadores inigualables del Siglo de Oro, sino a otros palpables en muestras artísticas, literarias, históricas y también arqueológicas, dignas de sumarse al legado europeo, como lo habían sido antes las del Creciente Fértil y Grecia, transitados por diplomáticos y anticuarios. Además, coetáneamente, ingenieros de minas de la Europa industrial, como Sandars (1852-1922) o Siret (1860-1934), se asombraban de la abundancia de hallazgos arqueológicos en las áreas de sus concesiones en España y daban a conocer el alto desarrollo de la sociedad peninsular en la Edad del Bronce (Siret, 1888).

En cierto sentido los eruditos europeos vieron en España el Oriente de Occidente (Neutres, 2002: 78), aunque no se comportaron aquí como allí lo había hecho, porque no viajaron a España para reforzar los cimientos de su llustración sino atraídos por un país que se había mantenido libre de aquellos cánones. Sería, por tanto, erróneo equiparar hispanismo y orientalismo o helenismo, de entrada porque el primero es un fenómeno típico de un siglo XIX que admira lo primario como auténtico, cuando, cuestionando lo académico, Europa se reconoce en su herencia ante-romana, como bien refleja la admiración por Stonehenge en Gran Bretaña (Castleden, 1993) o la creación del Musée des Antiquités nationales de Saint-Germain-en-Laye por Napoleón III (1808-1873) en una Francia que siguió teniendo su buque insignia cultural, sin lugar a dudas, en el Louvre.

Es importante asimismo considerar que los arqueólogos que se interesaron entonces por España no pueden engrosar indiscriminadamente la lista de los hispanistas. Para agruparlos en ese círculo habría que advertir en sus obras el reconocimiento de las raíces de la creatividad española, valorándola de manera distinta a como lo hicieron historiadores y filólogos, puesto que la van a captar con más evidencia en los restos autóctonos anteriores a la era cristiana que en las cerámicas griegas, fenicias inscripciones latinas, o en los monumentos romanos, que, en tanto que testimonio de adscripción al Mediterráneo o a Roma, atrajeron a algunos investigadores a la Península —y también al norte de Áfricapara buscarse a sí mismos.

Sin embargo, lo que motiva a los primeros arqueólogos hispanistas es la apuesta por culturas ajenas al clasicismo, distintas de las que consagraron los viajeros ilustrados hispanistas que les precedieron, como fue el caso de Laborde (1773-1842) (1811) (Tormo, 1943: 259-304).

Los arqueólogos destacados en las líneas que siguen están algo más próximos al paisaje humano que les ofrece una España que recorren en mulo o en bicicleta, que pendientes de las fuentes escritas, actitud que tiene un reflejo claro y sencillo en lo que dijo Mérimée (1803-1870), autor que, si bien conocía las antigüedades clásicas, no las percibió en Sagunto (fig. 2) ya que, como un Quijote, abogaba aquí por algo más rural, porque era a Sancho a quien consideraba genuinamente español: 
Les antiquités, surtout les antiquités romaines, me touchent peu. Je ne sais comment je me suis laissé persuader d'aller à Murviedro, voir ce qui reste de Sagonte. J'ai gagné beaucoup de fatigue, j'ai fait de mauvais diners, et je n'ai rien vu du tout... .... Mon excursion à Murviedro ne m'a pas ennuyé pourtant. J'ai loué un cheval et un paysan valencien pour m'accompagner à pied. J'ai trouvé (le Valencien) grand bavard, passablement fripon, mais en somme bon compagnon et assez amusant. Mérimée (1874: 330-359)

Figura 2. Planta de Sagunto publicada por A. de Laborde en 1811.

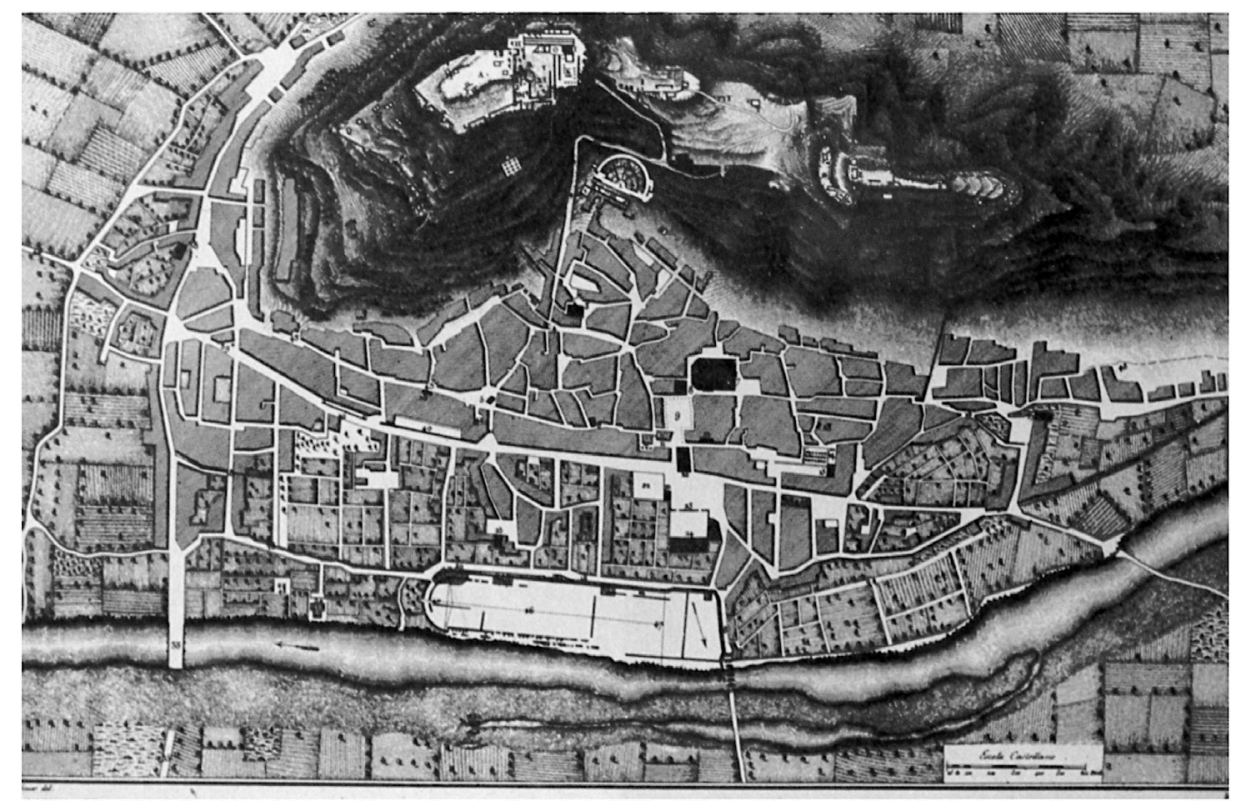

\section{LA CULTURA IBÉRICA}

En este caso centraré mi atención en los hispanistas que reconocieron la cultura que hoy se denomina ibérica y se data entre los siglos $\mathrm{V}$ y I a. C., advirtiendo, en consecuencia, que la balanza se va a inclinar hacia Francia (Rouillard, 1995: 105-112. Id., 1999: 25-32). Trataré de esbozar su ambiente cultural en el tránsito del siglo XIX al XX, sus instituciones y, en especial, el perfil de las personas de mi campo de competencia, ampliando el panorama hacia otros países, sin pretensiones exhaustivas.

El punto de partida que propongo es relacionar el logro francés de enviar misiones arqueológicas a España (Mora, 2004: 27-42) con el clima impulsado por hispanistas pioneros. Los arqueólogos contaron no solo con el respaldo extraoficial de revistas ilustradas, ya que había lectores interesado en el tema, sino también con el soporte oficial de las universidades de Burdeos y de París-Sorbona, del Ministerio de Instrucción Pública y de la Academia de Bellas Artes, así como con el firme apoyo del Museo del Louvre. Fueron misiones bien financiadas que cumplieron objetivos, en contraposición con la proverbial escasez de recursos públicos españoles para excavaciones arqueológicas. En paralelo surgieron el Bulletin hispanique (1899), la École de hautes Études hispaniques (1909) (Thamin, 1909: 328-332), a la que significativamente se asoció el Institut de hautes Études ibériques (1937), cuyos estudios, en buena medida arqueológicos, salieron del medio especializado cuando se proyectaron hacia el gran público, al más alto nivel en el momento en que se exhibieron emblemáticas piezas ibéricas en el Louvre. Cuando este museo dejó de adquirirlas tras la promulgación en España de la Ley de Excavaciones y Antigüedades de 1911, fue un 
arqueólogo llamado Pierre Paris quien desplegó argumentos a favor de seguir cultivando el hispanismo, que culminaron en la Casa de Velázquez de la Ciudad Universitaria, creada en 1920, abierta en 1928, destruida en la Guerra Civil (1936-1939), reconstruida en 1958 y vigente hasta hoy.

Así como Delaunay (1994) ha analizado con criterio propio lo aventurada que fue para Francia la relación con España (y con su patrimonio arqueológico) a comienzos del siglo XX, la formación de un fondo ibérico en el Museo del Louvre (Rouillard, 2006), favorablemente recibido por la sociedad francesa, no ha sido objeto de estudios que aborden su razón de ser. Se trata de un hecho muy particular, fundamental por su trascendencia, que ningún otro gran museo secundó fuera de España. El promotor de esta iniciativa fue Heuzey (Monceaux, 1922: 53-56), convencido de la oportunidad de revelar al mundo esta primicia, por lo que no solo se empeñó en la depuración de las falsificaciones atribuidas al santuario del Cerro de los Santos, en estrecha colaboración con Mélida (Casado, 2006), sino que también desplegó toda su sólida autoridad académica a favor de la autenticidad del arte ibérico (Heuzey, 1891: 608-615).

La evidencia de que la veintena de cabezas del Cerro de los Santos expuestas en la Salle Ibérique atrajeron a la vanguardia artística que buscaba en París formas nuevas y libres, se constató mediante su asociación con Picasso (1881-1973), que tuvo un par de ellas en su estudio en 1906 (fig. 3) (Johnson Sweeney, 1941: 191-198). A pesar de que esto fuera a resultas de una sustracción, totalmente ajena al pintor, quien tuvo que retornarlas al Louvre (Aranegui, 2012: 131-148), la confluencia de un maestro del cubismo con obras ibéricas que, según algunos de sus biógrafos (Mallén, 1997-2013), le sirvieron de fuente de inspiración (fig. 4), contribuyó a popularizar la escultura ibérica, en la línea del hispanismo del momento, sin que esto fuera entonces valorado en España.

Figuras 3 a y b. Cabezas del Cerro de los Santos que estuvieron en el estudio de Picasso en París en 1906
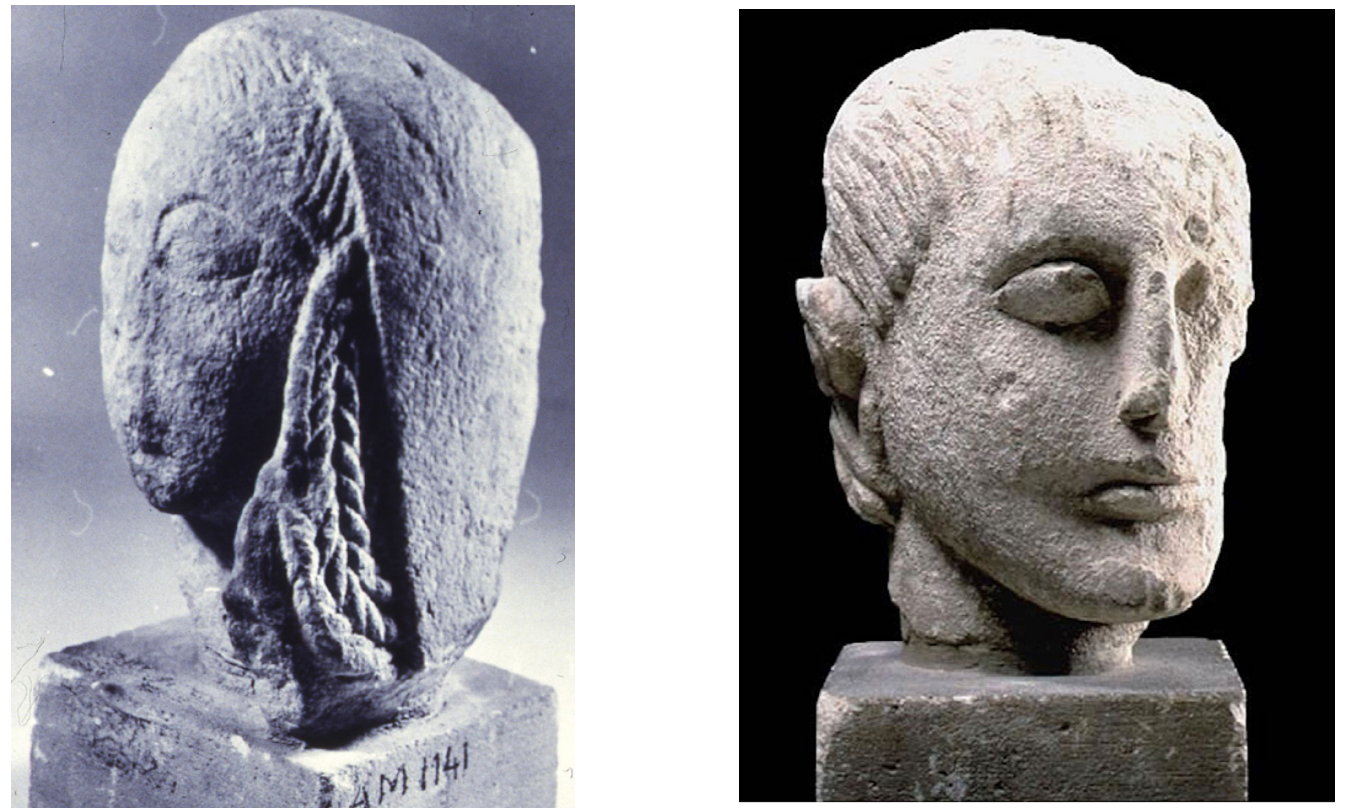

Fuente: Museo del Louvre 
Figura 4. Picasso: presunta influencia de la estética ibérica en Les Demoiselles d'Avignon, detalle

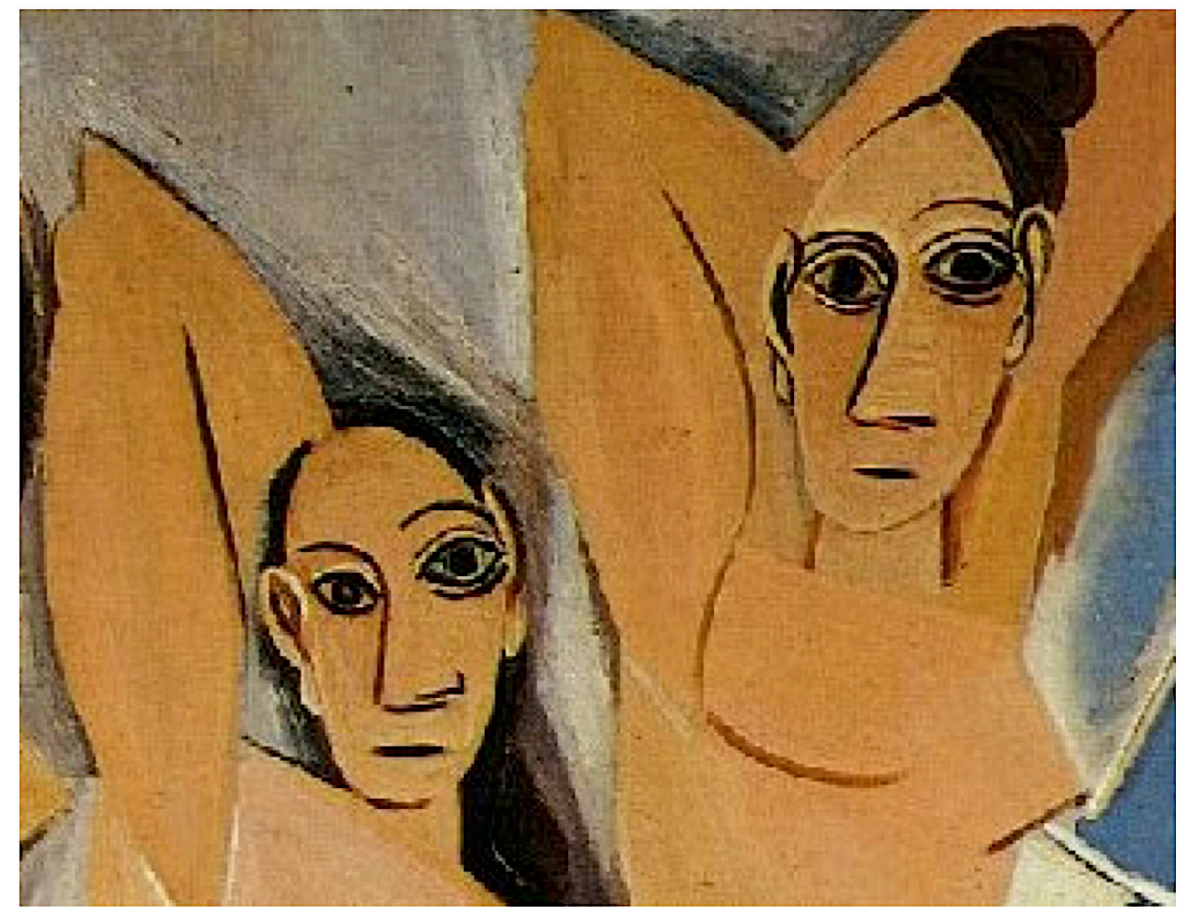

Fuente: Museum of Modern Art

Las misiones se iniciaron en 1886 y siempre estuvieron a cargo de expertos acreditados por su formación en las prestigiosas Écoles francesas (ENS-Ulm en París, Roma, Atenas...). Engel (1855-1935) aparece en primer lugar, dotado de una notable capacidad profesional y con unas aptitudes sociales que le llevan a colaborar con el arqueólogo privado y marchante de antigüedades Bonsor (1855-1930) (Peñalver, 2011), así como a establecer amistad con los propietarios de lugares arqueológicos, como el Dr. Campello en Elche y su pariente el cronista Pedro Ibarra (1858-1934). Sus primeros pasos se encaminan a Osuna (López García, 2008: 141-147; Ruiz Cecilia, 2016: 83-99), escenario de la batalla de Munda (45 a. C.), un hito del ascenso de César (100-44 a. C.), obligadamente tratado en sus publicaciones (Engel, 1893; Engel y Paris, 1999; Ruiz Cecilia y Moret, 2009), aunque pronto se decanta por la adquisición de monedas y piezas artísticas ibéricas susceptibles de ser mostradas en Francia, lo que le obliga a recorrer un área extensa del sureste peninsular. Detrás de esta trayectoria sigue estando Heuzey, conservador del Departamento de Antigüedades Orientales del Louvre desde 1870, con experiencia previa en el Mediterráneo oriental, que pone en juego su reputación si esta misión fracasa. Para asegurar su éxito despliega una estrategia asociada a un triunfo de César que ya había practicado en Grecia al intentar localizar la batalla de Farsalia (48 a. C.), a pesar de su desinterés por la historia militar. Así secundaba la política desplegada por Napoleón III entre 1852 y 1870, siempre privilegiada por su país.

Al amparo de este propósito, Heuzey desarrolló en Grecia actuaciones más acordes con su manera de pensar: se interesó por el arte figurativo, idóneo para hacer visibles los resultados de su trabajo en el Louvre, arte que, sumado a las peculiaridades antropológicas del paisanaje, le produjo mayores satisfacciones que la victoria de César. Algo muy parecido se observa después en Engel, que se identifica con una Andalucía de la que quedó prendado, en la que descubre relieves y esculturas, notablemente en Osuna, precisamente con representaciones guerreras (fig. 5), que aumentan hacia 1903 la colección ibérica del Louvre sin necesidad de explicar la batalla de Munda. 
Figura 5. Fragmento de la decoración de un monumento funerario de época romana de Osuna (Sevilla)

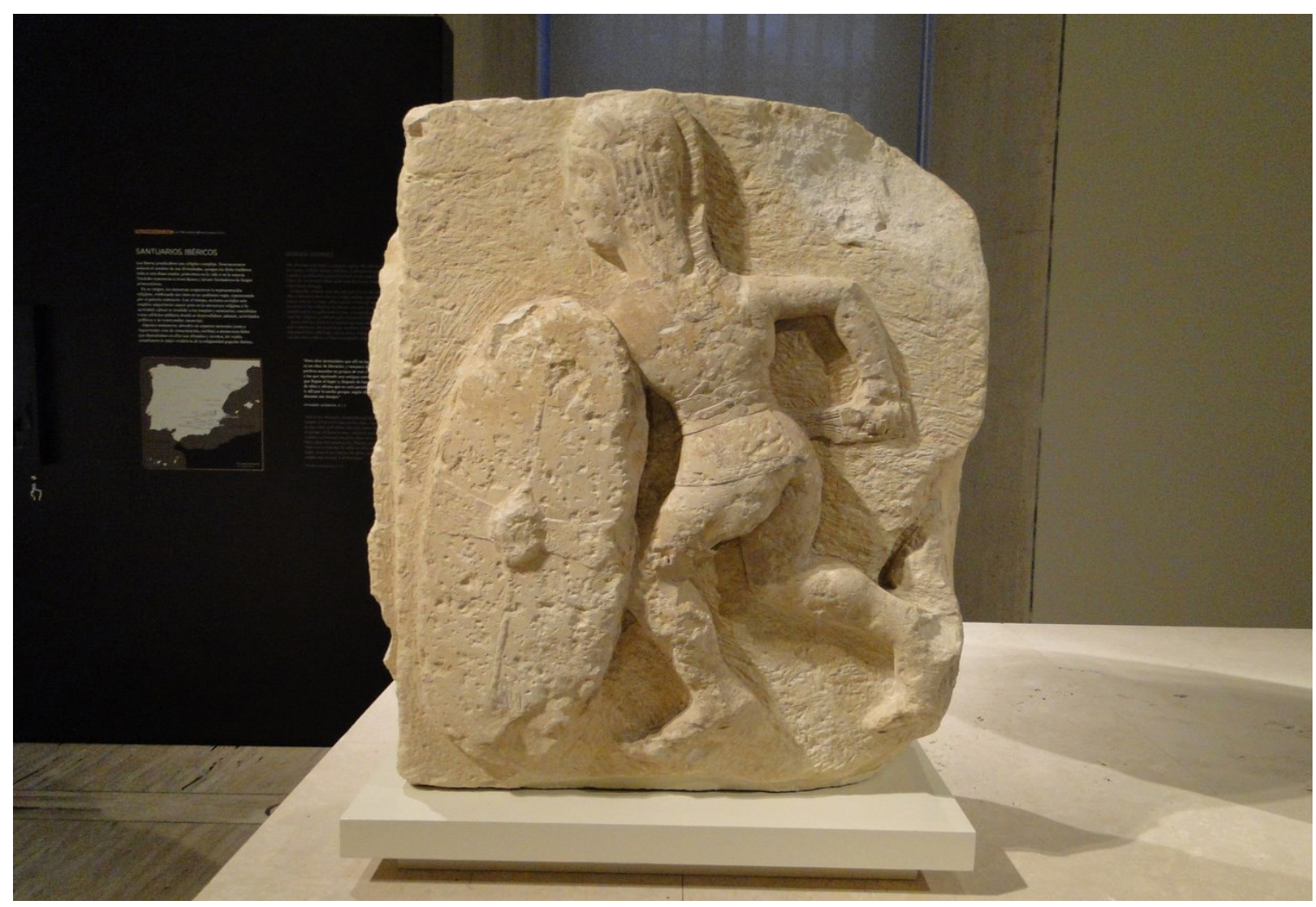

Fuente: Museo Arqueológico Nacional

El siguiente arqueólogo encaminado por Heuzey y Engel hacia España es Paris (18591931) (Paris, 1979; Reimond, 2018: 156-182), otro personaje decisivo en el tema que nos ocupa, que fue director de la Casa de Velázquez, donde falleció. Viaja a España en 1885 pero no desarrolla una actividad arqueológica hasta colaborar en el esclarecimiento del affaire del Cerro de los Santos y asumir principalmente la vigilancia de los yacimientos de Albacete, Murcia y Alicante que a Engel le quedaban distantes. Es entonces cuando experimenta su particular conversión al hispanismo ya que tiene la fortuna de asistir al hallazgo en 1897 de la Dama de Elche que, gracias a la eficacia de sus contactos y sintonía con Heuzey (1897: 505-509), puede ingresar en la colección del Louvre y erigirse en prueba incuestionable de las raíces míticas hispanas, bien definidas en las líneas siguientes:

Elle est orientale par le luxe de ses joyaux, par un je ne sais quoi que le sculpteur a conservé, la modelant, de ses plus anciens maîtres, par les traditions de métier qu'on trouve encore vivaces ; elle est grecque, elle est attique par une inexprimable fleur de génie qui la parfume comme ses sœurs de l'Acropole ; elle est surtout espagnole, par la surcharge de sa mitre et des grandes roues qui entourent sa tête fine, par l'étrangeté troublante de sa beauté. Elle est plus qu'Espagnole, elle est l'Espagne même, elle est l'Ibérie, sortant, rayonnante encore de jeunesse, de son tombeau plus de vingt fois séculaire. Paris (1903-1904: 308-309) 


\section{LA DAMA DE ELCHE COMO CONCLUSIÓN}

Pour la gloire d'Elche, pour la glorie de l'Espagne, pour celle du docteur Campello. Paris (1907: 323)

Figura 6. La Dama de Elche, siglo IV a. C.

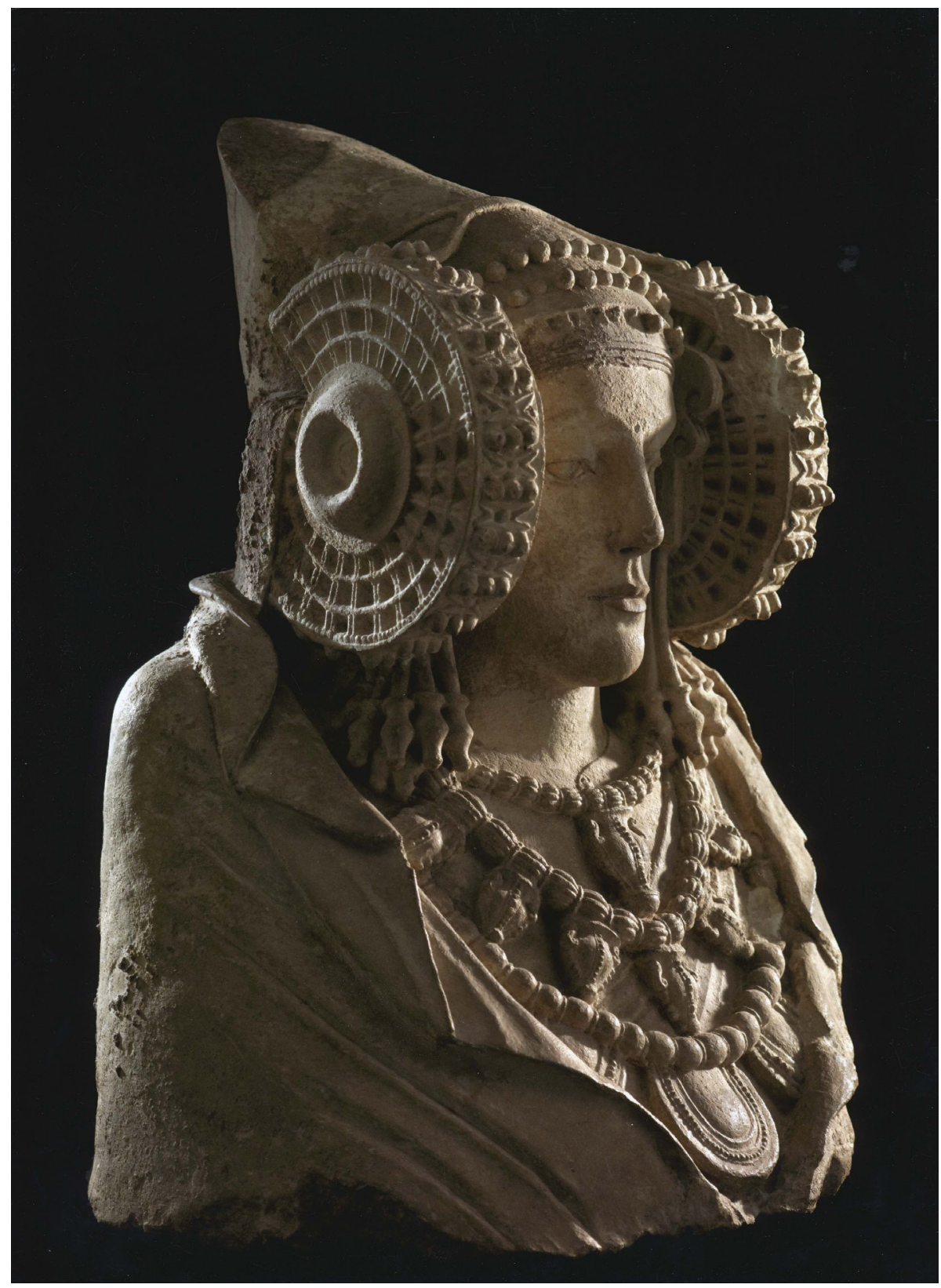

Fuente: Museo Arqueológico Nacional

La Dama de Elche (fig. 6), libre de sospechas de pertenecer a la época visigoda, exponente de una técnica de esculpir que le confiere un estilo desconocido en el circuito académico de su tiempo, ingresó en el Museo del Louvre con el número de registro AM 859 y fue expuesta en una sala donde había piezas de Chipre y de Palmira (Tadmir, Siria), con la más que probable intención de mostrar la extraordinaria pervivencia de la huella oriental en Iberia, además de sugerir la conveniente intervención arqueológica francesa en estos lugares. El espacio expositivo forzaba una cierta comparación de la Dama con 
la reina Zenobia (245-274 d. C.), famosa por su valeroso temple, de una época mucho más avanzada pero reclamo atractivo para el gran público, por el éxito del relato del viaje a Oriente de Lady Hester Stanhope (1776-1839), conocida como la Reina Blanca de Palmira, narrado por el médico privado que la acompañó en su expedición (Meryon, 1845). Se sabía que esta aristócrata había sido amada por el general John Moore (1761-1808), caído en Galicia al comienzo de la guerra de la Independencia, y que había tenido amistad con Lord Byron (1788-1824). Heroína, en suma, a la que acompañó una sugerente dama anónima del otro extremo del Mediterráneo, esculpida en el siglo IV a. C. y presentada por arqueólogos conscientes de la repercusión positiva de los detalles sentimentales sobre la sociedad romántica.

Cuando los fondos ibéricos del Louvre aumentaron a comienzos del siglo XX con las piezas de Osuna, Agost, Llano de la Consolación y Cerro de los Santos, se habilitó la sala VII como Salle Ibérique (fig. 7) pero en ella no se incluyó el original de la Dama, lo que es significativo, sino una reproducción, autorizada por Heuzey y por Pottier (1855-1934), realizada por Ignacio Pinazo Martínez (1883-1970) en 1907 por encargo de Mélida, entonces director del Museo de Reproducciones Artísticas de Madrid (Aranegui, 2018: 118-120).

Figura 7. Un sector de la Salle Ibérique hacia 1907

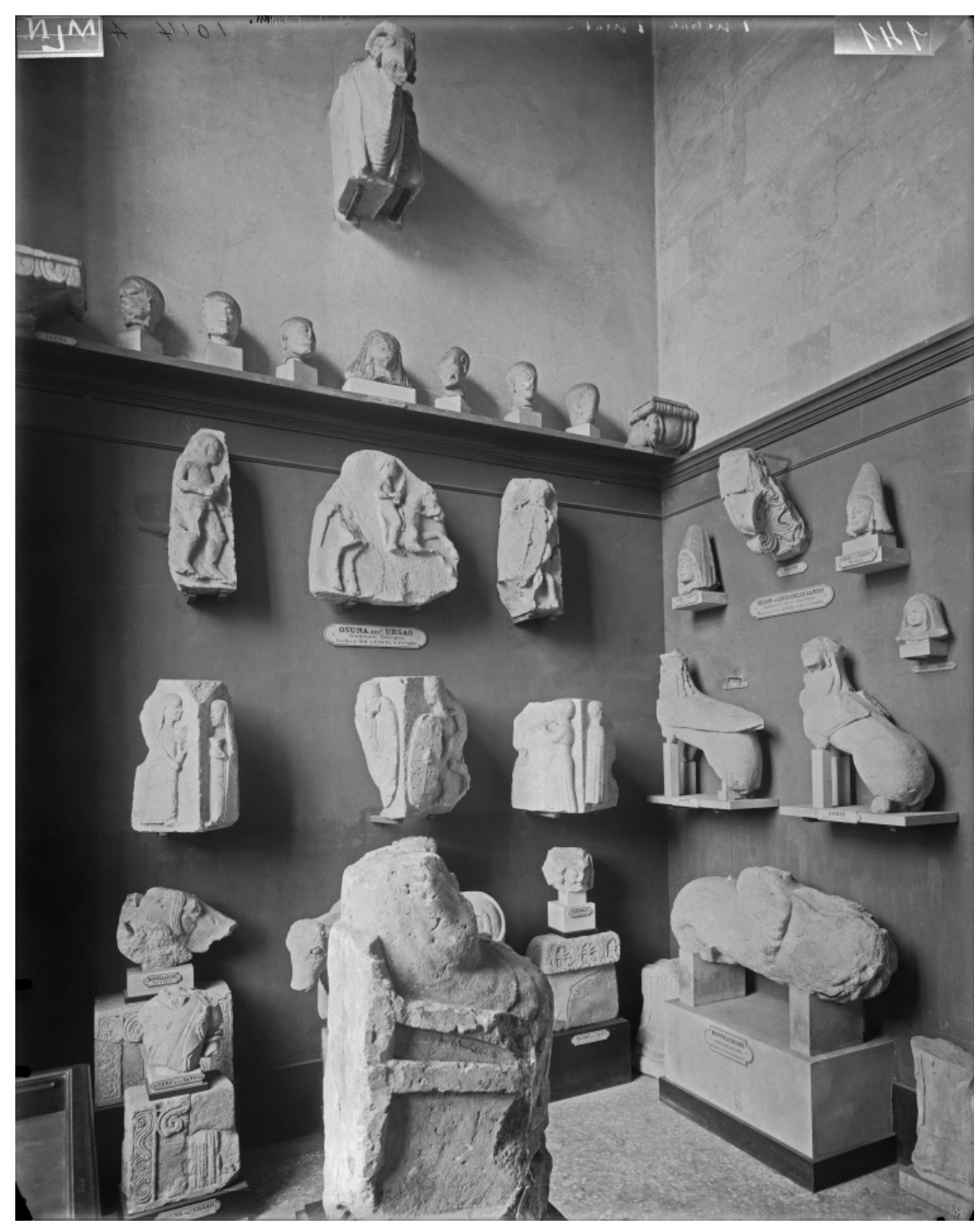

Fuente: cortesía del Museo del Louvre 
Desde el Museo del Louvre, la Dama de Elche recabó la atención de arqueólogos franceses, ingleses y alemanes, junto a algunos españoles, como indica una bibliografía internacional especializada superior en títulos a la dedicada al Cerro de los Santos y que ninguna otra muestra ibérica ha vuelto a reunir. Pero este interés fue languideciendo a medida que el busto se asociaba al presente, ya fuera a través del reconocimiento de García Lorca durante su estancia en Nueva York en 1929, o, en otros términos, mediante la consideración de sus aderezos como antecedentes de los de las labradoras valencianas, o bien a partir de la adopción de su atuendo por María Teresa León en la despedida de las Brigadas Internacionales en Valencia, y de Margarita Xirgú en la gira por Argentina de la versión de Rafael Alberti de la Numancia cervantina (Aranegui, 2018: 135-136). Para estos creadores la Dama fue la España cosmopolita, exiliada en París, que añoraban. Para la Segunda República, un emblema, utilizado en la emisión de billetes de cien pesetas en 1938 (Tortella, 2008: 331-368).

Ignacio Pinazo hizo más de cincuenta copias de la reproducción del busto pues, aprovechando el interés que los hispanistas acrecentaron y los anticuarios de arte español nutrieron, hubo una cierta demanda de esta imagen. El fundador de la Hispanic Society of America, Archer M. Huntington (1870-1955), no solo compró un ejemplar sino que también pagó la campaña de excavaciones que hizo Albertini (1880-1841) en La Alcudia de Elche en 1905. El Metropolitan Museum, la Casa de España en Nueva York, el Museo Británico, las ciudades de Lyon, Burdeos, Bruselas, Viena, Moscú..., adquirieron sus correspondientes vaciados mientras que, excepción hecha de Madrid, Valencia, Játiva y Murcia, la demanda española fue escasa y su promoción tardía si se compara con la de la Gran Oferente del Cerro de los Santos, cuyo vaciado estuvo en las principales exposiciones universales. Hasta la década de 1920 no se prodiga en España la admiración por la Dama de Elche que, sin embargo, ganó popularidad hacia 1930 como tema del cartel de la Exposición Internacional de Barcelona (1929) y del banco de azulejos de Alicante del Homenaje a la Hispanidad en la Plaza de España de la Exposición Iberoamericana de Sevilla (1929), reproduciéndose en el mobiliario urbano de Elche y de Valencia e interesando a los pintores y escultores de entonces y de nuestro tiempo.

A medida que España acoge a la Dama en su imaginario, la convierte en símbolo de una identidad excluyente, regionalista, que Llorente Falcó describió así:

La Dama de Elche, que en los primeros tiempos después de su descubrimiento solo tenía un valor arqueológico, comienza a mirarse desde otros puntos de vista; ya no es el curioso documento de piedra de las edades pasadas, atestiguador de una civilización y de una cultura artística, sino la personificación de la mujer ibérica, de aquella raza que constituye el fundamento de la española. Llorente Falcó (ABC, 23 de junio de 1929)

De este modo se culmina un proceso de separación de la pieza no solo de su contexto, como había comenzado a hacerse en el Louvre, sino también de su historia y de su historiografía, porque es el presente de España el que le da sentido, sin que la cultura que la creó cuente lo más mínimo.

Eran momentos en los que iba ganando fuerza otro símbolo de la identidad propiamente española ligado a la bravura ante la adversidad y al desafío a la muerte, asociado a hechos bélicos. De ahí que las modestas ruinas de Numancia, identificadas por Saavedra (1829-1912) en la Muela de Garray (Soria) (Jimeno, 2000: 175-193), fueran destacadas con un obelisco en 1886 y pasaran a representar la esencia patria, incluso para Mélida, con el soporte literario de la tragedia de Cervantes (1547-1616), fundamental para su declaración como Monumento Nacional en 1882. En torno a este cambio de valores se 
produjo un cambio de orientación de los hispanistas arqueólogos, con Schulten (1870-1960) auto-situado en primera línea, pese a su mediocridad académica, como colofón de una competente colaboración alemana anteriormente especializada en epigrafía latina pero que también había mostrado interés por la Dama de Elche (Hübner, 1898: 114-134). Schulten no tuvo nada que ver con la bonhommie francesa. Se enemistó con muchos arqueólogos sorianos, aunque tuvo aceptación entre los catalanes, que le nombraron doctor honoris causa. Numancia consiguió la financiación del káiser Guillermo II (1859-1941) para las excavaciones (Schulten, 1914), fue visitada por Alfonso XIII y elevó la reputación de Schulten en una España necesitada de mitos que demostraran su fuerza (Wulff, 2004). Los materiales de los campamentos romanos del sitio de Numancia siguen depositados en Maguncia y su revisión reciente demuestra la superficialidad con que los entendió Schulten.

Pero esta no fue la tónica de los arqueólogos alemanes. Entre otros, Untermann (19282013) merece ser considerado un hispanista modélico. Fue durante toda su vida un gran investigador de las lenguas paleoibéricas, cuyos testimonios fue recogiendo y publicando sistemáticamente entre 1975 y 1997.

En términos generales, hasta los años 1940 puede hablarse de arqueólogos hispanistas. El énfasis que supuso el descubrimiento francés del arte ibérico dejó de latir en 1941, cuando tuvo lugar el intercambio de objetos artísticos acordado por Pétain y Franco (Gruat y Martínez, 2011) y la Dama de Elche pasó al Museo del Prado, que nunca le destinó propiamente una sala. Después solo muy puntualmente aparece algo relacionado con la arqueología hispanista, pues los extranjeros que continúan excavando en este país dejan de estar motivados por la singularidad ibérica y ya no insisten en sus peculiaridades. Los trabajos de Nicolini (1973) son uno de los epílogos de este post-hispanismo. Más tarde, lo ibérico que quedaba en el Louvre se traslada a Saint-Germain-en-Laye, abandonando en 1982 el prestigioso edificio que lo dio a conocer, y, finalmente, la representación de la Dama es eliminada de la cubierta del Bulletin hispanique en 2009.

El hispanismo arqueológico fue hermoso mientras duró, pero duró poco tiempo. Se trata, por lo tanto, de un tramo breve, no exento de interés, de una especialidad que sigue viva.

Tras nuestra Guerra Civil, aquel clima y tono estético pasaría del territorio liberal y sus filas a la retórica del franquismo. Esta habría de enfocar el arraigado hispanismo y el nacionalismo en las conciencias colectivas de nuestro país, agrandando en su relectura la memoria de una hispanidad imperial y colonizadora, anclándola estéticamente en imágenes grandilocuentes, plasmadas en metáforas enfáticas y obsoletas para aquellas fechas. Pena (2012: 19)

\section{BIBLIOGRAFÍA}

Aranegui, C. (2012): Los Iberos ayer y hoy. Arqueologías y culturas, Madrid, Marcial Pons. - (2018): La Dama de Elche. Dónde, cuándo y por qué, Madrid, Marcial Pons

Ayarzagüena, M., Mora, G. y Salas, J. A. (eds.) (2017): 150 años de historia de la arqueología: teoría y método de una disciplina, MAN, Madrid.

Canavaggio, J. (1987): Cervantes, Madrid, Espasa-Calpe.

Cartailhac. E. (1902): "La grotte d'Altamira, Espagne. Mea culpa d'un sceptique", L'Anthropologie 13, pp. 348-354.

Casado, D. (2006): José Ramón Mélida y la Arqueología Española, RAH, Madrid.

Castleden, R. (1993): The Making of Stonehendge, Londres y Nueva York, Routledge.

Chapa, T. y González Alcalde, J. (2013): "Las esculturas ibéricas del Cerro de los Santos en 
la Exposición Universal de Viena (1873)", Lucentum 32, pp. 115-130.

Delaunay, J.-M. (1994): Des palais en Espagne. L'École des hautes études hispaniques et la Casa de Velázquez au cœur des relations franco-espagnoles du XXe siècle (18981979), Casa de Velázquez, Madrid.

Díaz-Andreu, M., Mora, G. y Cortadella, J., eds. (2009): Diccionario Histórico de la Arqueología en España (siglos XV-XX), Madrid, Marcial Pons.

Duplá, A., Dell'Elicine, E. y Pérez Mostazo, J. (2018): Antigüedad clásica y naciones modernas en el Viejo y el Nuevo Mundo, Madrid, Polifemo.

Engel, A. (1893): Rapport d'une mission archéologique en Espagne, París, Ernest Leroux.

Engel, A. y Paris, P. (1999): Una fortaleza ibérica en Osuna (excavaciones de 1903), Ed. facsímil, Universidad de Granada.

Fernández de los Ríos, A. (1878): La Exposición Universal de 1878. Guía itinerario para los que la visiten, descripción razonada rara para los que no hayan de verla, recuerdo para los que la hayan visto, Madrid, English y Gras.

Gracia Alonso, F. (2011): Pere Bosch Gimpera. Universidad, política, exilio, Madrid, Marcial Pons.

Gruat, C. y Martínez, L. (2011): L'échange: Les dessous d'une négociation artistique entre la France et l'Espagne, 1940-1941, París, A. Colin.

Heuzey, L. A. (1891): "Statues espagnoles de style gréco-phénicien (question d'authenticité)", Bulletin de correspondence hellénique 15, pp. 608-625.

- (1897): "Le buste d'Elche et la mission de M. Pierre Paris en Espagne", Comptes rendus des séances de l'Académie des Inscriptions et Belles Lettres 41, 5, pp. 505-509.

Hübner, E. (1898): "Die Büste von Illici", Jahrbuch des Archaeologischen Instituts 13, pp. 114-134.

Jimeno, A. (2000): "Numancia: pasado vivido, pasado sentido", Trabajos de Prehistoria, 57, 2, pp. 175-193.

Johnson Sweeney, J. (1941): "Picasso and Iberian Sculpture", The Art Bulletin 23, 3, pp. 191-198.

Laborde, A. (1811): Voyage pittoresque et historique de l'Espagne, París, Pierre Didot.

Ladero, M.A.: (1996): “Imagen y representación de los otros: la 'decadencia' española como argumento historiográfico", Hispania Sacra 48, 97, pp. 5-50.

Lasheras, A.B. (2009): España en París. La imagen nacional en las exposiciones universales 1855-1900, Universidad de Cantabria, Santander.

Llorente, T. (1879): 1867 y 1878. Cartas sobre las dos últimas exposiciones universales de París y apuntes del viaje por Valencia, Valencia, Imprenta J. Domenech.

López García, I. (2008): "Arthur Engel y Pierre Paris: dos pioneros franceses en los viajes culturales por las regiones arqueológicas de España", Baetica, 30, pp. 141-147.

Mallén, E. (1997-2013): On-line Picasso Project.

Mélida, J. R. (1903a): "Las esculturas del Cerro de los Santos. Cuestión de autenticidad", RABM VII, 2, pp. 85-90.

- (1903b): "Las esculturas del Cerro de los Santos. Cuestión de autenticidad", RABM VII, 6, pp. 470-485.

- (1903c): "Las esculturas del Cerro de los Santos. Cuestión de autenticidad", RABM VII, 8-9, pp. 140-148.

- (1903d): "Las esculturas del Cerro de los Santos. Cuestión de autenticidad", RABM VII, 8-9, pp. 247-255.

- (1903e): "Las esculturas del Cerro de los Santos. Cuestión de autenticidad", RABM VII, 11, pp. 365-372.

— (1904a): "Las esculturas del Cerro de los Santos. Cuestión de autenticidad", RABM VIII, 
10, pp. 43-50.

- (1904b): "Las esculturas del Cerro de los Santos. Cuestión de autenticidad", RABM VIII, 8/9, pp. 144-158.

- (1904c): "Las esculturas del Cerro de los Santos. Cuestión de autenticidad", RABM VIII, 10, pp. 276-287.

- (1905a): "Las esculturas del Cerro de los Santos. Cuestión de autenticidad", RABM IX, 1, pp. 37-42.

- (1905b): "Las esculturas del Cerro de los Santos. Cuestión de autenticidad", RABM IX, 2, pp. 19-38.

Méndez, L.R. (2006): "La Gran Exposición de Londres de 1851. Un nuevo público para el mundo, Artigrama 21, pp. 23-42.

Mérimée, P. (1874): La Venus d'Ille suivie de Djoumâne et Les sorcières espagnoles, París, Michel Lévy frères, pp. 330-359.

Meryon, C.L. (1845): Memoirs of the Lady Hester Stanhope as related by herself in conversation with her Physician, Londres, Henry Colburn Pub.

Monceaux, P. (1922): "Éloge funèbre de M. Léon Heuzey", Comptes rendus des séances de l'Académie des inscriptions et belles-lettres 66, 1, pp. 53-56.

Mora, G. (2004): "Pierre Paris y el hispanismo arqueológico", Tortosa, T. (coord.), El yacimiento de La Alcudia (Elche, Alicante): pasado y presente de un enclave ibérico, Anejos AEspA 30, Madrid, pp. 27-42.

Mora, G., Papí, C. y Ayarzagüena, M. (2008): Documentos inéditos para la historia de la Arqueología, Sociedad Española de Historia de la Arqueología, Madrid.

Neutres, J. (2002): Genet sur les routes du sud, París, Fayard.

Nicoloini, G. (1973): Les Ibères. Art et civilisation, París, Fayard.

Niño, A. (1988): Cultura y diplomacia: los hispanistas franceses y España de 1875 a 1931, CSIC-Casa de Velázquez-Societé des Hispanistes Français, Madrid.

- (e.p.): "El hispanismo francés y la cultura española del franquismo", Simposio Internacional: Cultura y ciencia nacionales en el primer franquismo (1939-1959), Universitat Pompeu Fabra, Barcelona.

Ortiz, J. (1807): Viaje arquitectónico-anticuario de España. Descripción del Teatro Romano de Sagunto, Madrid.

Papí, C., Mora, G. y Ayarzagüena, M. (eds.) (2012): "El patrimonio arqueológico en España en el siglo XIX: el impacto de las desamortizaciones", en I Jornadas Internacionales de Historiografía Arqueológica, Sociedad Española de Historia de la Arqueología y Museo Arqueológico Nacional, Madrid.

Paris, P. (1897): "Buste espagnol de style Gréco-Asiatique trouvé à Elche (Musée du Louvre)", Monuments et mémoires de la Fondation Eugène Piot 4, 2, pp. 137-168.

- (1903-1904): Essai sur l'art et l'industrie de l'Espagne primitive, París, Ernest Leroux.

- (1907): "Promenades archéologiques en Espagne. II Elche", Bulletin hispanique 9, 4, pp. 317-334.

- (1979): L'Espagne de 1895 et 1897. Journal de voyage, Centre Pierre Paris, París.

Pellistrandi, B. (2013): Histoire de l'Espagne. Des guerres napoléoniennes à nos jours, París, Perrin.

Pena, C. (2012): Territorios sentimentales. Arte e identidad, Madrid, Biblioteca Nueva.

Peñalver Simó, M. (coord.) (2011): El Castillo de Mairena del Alcor. El legado de Jorge Bonsor y Dolores Simó. Memorias y recuerdos, Servicio de Archivo y Publicaciones. Diputación de Sevilla y Ayuntamiento de Mairena del Alcor, Sevilla.

Pierce, A. y Jones, C. A. (dirs.) (1962): Actas del Primer Congreso Internacional de Hispanistas, Oxford, The Dolphin Book. Co. Ltd. 
Reimond, G. (2018): "Arcaísmo y clasicismo en el pensamiento de Pierre Paris: los escultores griegos a la conquista del movimiento", Duplá, A., Dell'Elicine, E. y Pérez Mostazo, J. (eds.), Antigüedad clásica y naciones modernas en el Viejo y el Nuevo Mundo, Madrid, Polifemo, pp. 156-182.

Rouillard, P. (1995): "Le Pays Valencien et les archéologues français du XIXe siècle", Saguntum 29, pp. 105-112.

— (1999): “A. Engel y P. Paris y los primeros pasos en los Estudios Ibéricos”, Blánquez, J. y Roldán, L. (eds.), La cultura ibérica a través de la fotografía de principios de siglo. Un homenaje a la memoria 1, Madrid, pp. 25-32.

- (2004): "Pierre Paris", Zona Arqueológica 3, Pioneros de la arqueología en España. El proceso hacia la arqueología científica 1833-1912, pp. 317-320.

- (2006): "La Dame d'Elche et son séjour dans le Musée du Louvre", La Dama de Elche: figura y símbolo. Los lunes con La Alcudia, Elche.

Ruiz Cecilia, J.I. (2016): "La fotografía antigua como recurso para la investigación arqueológica en la provincia de Sevilla. Ejemplos de Carmona y Osuna", Actas del XI Encuentro provincial de investigadores locales. La fotografía, documento para la investigación, Diputación de Sevilla, pp. 83-99.

Schulten, A. (1914): Mis excavaciones en Numancia (1905-1912), Barcelona, Estudio.

Siret, H. y L. (1888): Les premières âges du métal dans le sud-est de l'Espagne, Bruselas, Impr. Polleunis, Ceuterick et Lefébure.

Thamin, R. (1909): "École de hautes Études hispaniques à Madrid (Espagne et Portugal)", Bulletin hispanique 11, 3, pp. 328-332.

Tormo, E. (1943): "El centenario de Alexandre Laborde, el hispanista magnánimo", BRAH 113 , pp. 259-304.

Tortella, T. (2008): "El billete español en la edad contemporánea: mucho más que un medio de pago", VII Jornadas científicas sobre documentación contemporánea (1868-2008), Universidad Complutense, Madrid, pp. 331-368.

Tortosa, T. (2017): "La 'Mostra Internazionale di Archeologia' en Roma (1911). El patrimonio español como espejo internacional", Ayarzagüena, M., Mora, G. y Salas, J. A. (eds.), 150 años de historia de la arqueología: teoría y método de una disciplina, MAN, Madrid, pp. 1133-1147.

Untermann, J. (1975): Monumenta Linguarum Hispanicarum. I. Die Münzlegenden. Wiesbaden.

- (1980): Monumenta Linguarum Hispanicarum II: Die Inschriften in iberischer schrift aus Südfrankreich. Wiesbaden.

- (1990): Monumenta Linguarum Hispanicarum III: Die iberischen inschriften aus Spanien. Wiesbaden.

- (1997): Monumenta Linguarum Hispanicarum IV: Die tartessischen, keltiberischen und lusitanischen inschriften. Wiesbaden.

Wulff, F. (ed.) (2004): Historia de Numancia, de Adolf Schulten, Pamplona, Urgoiti. 